\title{
Two Siblings with Classical Xanthinuria Type 1: Significance of Allopurinol Loading Test
}

\author{
Kimiyoshi Ichida, Mayumi Yoshida, Ryozou SaKuma* and Tatsuo Hosoya
}

\begin{abstract}
Two brothers with classical xanthinuria who lacked xanthine dehydrogenase activity were encountered. Their hypouricemia was caused by underproduction of uric acid. In their duodenal mucosa, no xanthine dehydrogenase (oxidase) activity was detected. The patients had no symptoms except for duodenal ulcer in one case. The conversion of allopurinol to oxipurinol during an allopurinol loading test for determining the type of classical xanthinuria revealed that the patients had classical type 1 xanthinuria, because aldehyde oxidase activity was present. Furthermore, the allopurinol loading test was conducted to determine the optimal examination times and specimens required for this test.
\end{abstract}

(Internal Medicine 37: 77-82, 1998)

Key words: xanthine dehydrogenase, xanthine oxidase, aldehyde oxidase, duodenal ulcer

\section{Introduction}

Xanthine dehydrogenase (xanthine oxidase) is an important enzyme that catalyzes the oxidation of hypoxanthine to xanthine and uric acid from xanthine during the final stage of purine metabolism. Classical xanthinuria, due to a lack of xanthine dehydrogenase activity, is characterized by hypouricemia, reductions in urinary uric acid excretion, and increases in the serum and urinary xanthine and hypoxanthine concentrations. Classical xanthinuria was first reported by Dent and Philpot in 1954 (1). It is transmitted as an autosomal recessive disease with no chromosomal abnormalities. In Japan, only about 20 cases have been reported (2-5). The clinical symptoms include myositis due to tissue deposits of xanthine and urinary tract calculi caused by increased urinary excretion of xanthine. It was reported that the variations in allopurinol metabolism existed in patients with classical xanthinuria, because some xanthinuric patients could metabolize allopurinol to oxipurinol (6). Recently, classical xanthinuria was classified into the following two types (7): type 1, a deficiency of xanthine dehydrogenase alone and type 2, deficiencies of xanthine dehydrogenase and aldehyde oxidase. Since both xanthine dehydrogenase and aldehyde oxidase metabolize allopurinol, a xanthine dehydrogenase inhibitor, to oxipurinol, types 1 and 2 are differentiated by administering allopurinol and measuring oxipurinol in the serum or urine (7). In the present paper, two brothers with classical type 1 xanthinuria are reported and the allopurinol loading test was conducted to determine the optimal examination times and specimens required for this test.

\section{Case Reports}

These patients were brothers and the sons of a consanguineous marriage. Case 1 (propositus) was a 34 -year-old male, in whom hypouricemia was found during a routine health examination, and came to our hospital for further medical care. His laboratory data showed low serum uric acid and urinary uric acid excretion (Table 1). He had moderate gastritis and a duodenal ulcer, but no myositis or urolithiasis. Other examinations, including that of renal and liver functions, were normal.

Case 2 was a 35-year-old male, the elder brother of case 1 . Since classical xanthinuria was suspected in Case 1, this patient was examined for the disease. His serum uric acid and urinary uric acid excretion also were low (Table 1). He did not have a duodenal ulcer, myositis, or urolithiasis.

Though their father interestingly suffered from gout, it might be secondary because he had hypertension and renal insufficiency, and had taken antihypertensive medicines. Their mother did not have any past history of diseases.

From the Second Department of Internal Medicine, the Jikei University School of Medicine, Tokyo and *the Department of Clinical Chemistry, Toranomon Hospital, Tokyo

Received for publication May 6, 1997; Accepted for publication October 8, 1997

Reprint requests should be addressed to Dr. Kimiyoshi Ichida, the Second Department of Internal Medicine, the Jikei University School of Medicine, 3-25-8 NishiShinbashi, Minato-ku, Tokyo 105 
Table 1. Laboratory Data of Two Patients

Complete blood cell count and blood chemistry

\begin{tabular}{lrr}
\hline & Case 1 & Case 2 \\
\hline White blood cell $(\mathrm{WBC})(/ \mu \mathrm{l})$ & 6,200 & 7,480 \\
Red blood cell $(\mathrm{RBC})\left(\times 10^{4} / \mu \mathrm{l}\right)$ & 439 & 436 \\
Hematocrit $(\%)$ & 42.1 & 44.0 \\
Hemoglobin $(\mathrm{g} / \mathrm{dl})$ & 14.3 & 14.0 \\
Platelet $\left(\times 10^{4} / \mu \mathrm{l}\right)$ & 31.3 & 42.0 \\
Alanine aminotransferase $(\mathrm{mU} / \mathrm{ml})$ & 20 & 10 \\
Aspartate aminotransferase $(\mathrm{mU} / \mathrm{ml})$ & 29 & 14 \\
Lactate dehydrogenase $(\mathrm{mU} / \mathrm{ml})$ & 241 & 276 \\
Creatine phosphokinase $(\mathrm{mU} / \mathrm{ml})$ & 62 & 68 \\
Alkaline phosphatase $(\mathrm{BLu} / l)$ & 2.0 & 2.6 \\
Leucine aminopeptidase $(\mathrm{GRu})$ & 279 & 226 \\
$\gamma$-glutamyltranspeptidase $(\gamma-\mathrm{GTP})(\mathrm{mU} / \mathrm{ml})$ & 42 & 28 \\
Blood urea nitrogen $(\mathrm{BUN})(\mathrm{mg} / \mathrm{dl})$ & 11 & 12 \\
Creatinine $(\mathrm{mg} / \mathrm{dl})$ & 0.7 & 0.6 \\
Uric acid $(\mathrm{mg} / \mathrm{dl})$ & 0.1 & 0.5 \\
Na $(\mathrm{mEq} / l)$ & 143 & 143 \\
K (mEq/l) & 4.3 & 4.1 \\
Ca $(\mathrm{mEq} / l)$ & 4.7 & 4.3 \\
P (mg/dl) & 3.7 & 3.2 \\
\hline
\end{tabular}

Renal function

\begin{tabular}{lrr}
\hline$\beta_{2}-\mathrm{MG}(\mu \mathrm{g} / \mathrm{ml})$ & 1.3 & 1.1 \\
$\mathrm{U}-\beta_{2}-\mathrm{MG}(\mu \mathrm{g} / \mathrm{ml})$ & 96 & 228 \\
$\mathrm{U}-\mathrm{NAG}(\mathrm{U} / \mathrm{l})$ & 1.8 & 0.8 \\
$\mathrm{UUAV}(\mathrm{mg} / \mathrm{day})$ & 6.5 & 1.1 \\
$\mathrm{Ccr}(\mathrm{ml} / \mathrm{min})$ & 129 & 147 \\
\hline
\end{tabular}

Urinalysis

\begin{tabular}{llrr}
$\mathrm{pH}$ & & 6.5 & 8.0 \\
Protein & & $(-)$ & $( \pm)$ \\
Sugar & & $(-)$ & $(-)$ \\
Sediment & WBC & $0-2 / 1 \mathrm{~F}$ & $0-2 / 1 \mathrm{~F}$ \\
& RBC & $0-1 / 1 \mathrm{~F}$ & $0-1 / 1 \mathrm{~F}$ \\
\hline
\end{tabular}

$\beta_{2}$-MG: $\beta_{2}$-microglobulin, $\mathrm{U}-\beta_{2}$-MG: $\beta_{2}$-microglobulin in urine, $U$ NAG: $N$-acetyl- $\beta$-D-glucosaminidase in urine, UUAV: Urinary excretion of uric acid.

\section{Materials and Methods}

\section{Analyses of oxypurine, allopurinol, and oxipurinol levels}

Hypoxanthine, xanthine, uric acid, allopurinol, and oxipurinol were analyzed using high pressure liquid chromatography (HPLC) according to the modified method by Kojima et al (8).

\section{Allopurinol loading test}

The patients were instructed to refrain from drinking alcoholic beverages for one week prior to the test. The control
Table 2. Laboratory Data of Two Patients Related to Purine Metabolism

\begin{tabular}{lrr}
\hline & Case 1 & Case 2 \\
\hline Ccr (ml/min) & 129 & 138 \\
S-UA (mg/dl) & 0.1 & 0.4 \\
CuA (ml/min) & 1.13 & 0.17 \\
UuAV (mg/day) & 6.5 & 1.1 \\
S-HX (mg/dl) & 0.09 & 0.1 \\
S-X (mg/dl) & 0.37 & 0.24 \\
UhXV (mg/day) & 131.7 & 115.6 \\
UxV (mg/day) & 276.8 & 171.4 \\
UhX+XV/UhX+X+UAV & 0.99 & 0.99 \\
UXV/UhX+XV & 0.68 & 0.60 \\
XO activity (n mol/h/mg prot.) & 0 & 0 \\
(control: 47 n mol/h/mg prot.) & & \\
\hline
\end{tabular}

(Some data are from ref. 14)

S-UA: Serum uric acid, CUA: uric acid clearance, S-HX: Serum hypoxanthine, S-X: Serum xanthine, UHXV: Urinary excretion of hypoxanthine, $\mathrm{UxV}$ : Urinary excretion of xanthine, UHX+XV: Urinary excretion of oxypurine, $\mathrm{UHX}+\mathrm{X}+\mathrm{UAV}$ : Urinary excretion of total purine, $\mathrm{XO}$ activity: Activity of xanthine oxidase and xanthine dehydrogenase.

subjects were healthy 46- and 36-year-old males. Their serum uric acid and urinary excretion of uric acid were 5.4 and $5.5 \mathrm{mg} /$ $\mathrm{dl}$ and 689.6 and $449.1 \mathrm{mg} / \mathrm{day}$, respectively. Their clearance of creatinine and uric acid were 140.7 and $133.0 \mathrm{ml} / \mathrm{min}$ and 8.8 and $5.7 \mathrm{ml} / \mathrm{min}$, respectively. The dosage of allopurinol was determined according to the methods by Yamamoto et al and Hosoya et al $(5,9)$. The allopurinol loading test was conducted in the following manner: after P.O. administration of $300 \mathrm{mg}$ of allopurinol, urinary specimens were collected every 2 hours; the procedure was continued for 6 hours; and blood specimens were collected 1,3 , and 5 hours after administration of allopurinol. Allopurinol and oxipurinol contents were determined in the urine and serum. The presence of oxipurinol in serum and urine demonstrated the existence of xanthine dehydrogenase activity or aldehyde oxidaşe activity.

\section{Determination of xanthine dehydrogenase activity}

A control duodenal mucosa sample was obtained from the 36-year-old male mentioned above. Xanthine dehydrogenase activity was determined in the following manner: biopsy specimens of the duodenal mucosa were taken under endoscopy and the enzyme activity was determined using HPLC. The protein content was determined by the method of Lowry et al (10).

\section{Results}

\section{Purine metabolism}

As described in the case reports, both Cases 1 and 2 had markedly low serum and urinary uric acid levels. In both cases, 
urinary oxypurine excretions were increased and urinary xanthine excretions were mainly found in urinary oxypurine excretions (Table 2). Serum oxypurine levels were also high, mainly xanthine in both cases. Most total purine urinary excretions were oxypurine which is a precursor of uric acid in Cases 1 and 2. The xanthine dehydrogenase activity of the duodenal mucosa was below the detectable level in both cases. Based on these findings, both patients were diagnosed as suffering from classical xanthinuria.

\section{Allopurinol loading test}

Allopurinol loading tests were conducted on Cases 1 and 2 to determine the type of classical xanthinuria. Serum and urinary allopurinol levels in Cases 1 and 2 were similar to those in normal subjects (Fig. 1). Oxipurinol was detected in the first urine sample and the second serum sample of Cases 1 and 2, and the changes were similar to the changes in normal subjects (Fig. 2). Thus, the metabolism of allopurinol to oxipurinol demonstrated that Cases 1 and 2 suffered from classical xanthinuria type 1.

\section{Discussion}

Xanthine dehydrogenase exists as a dimer and each subunit has a molecular weight of 145,000 . It has four prosthetic groups (a molybdenum cofactor, two non-heme irons, and a FAD) in each subunit that participate in electron transport. Human xanthine dehydrogenase cDNA consists of 4002 nucleotides (11) and the human gene was mapped to chromosome $2 \mathrm{p} 23$ (12).

Classical xanthinuria types 1 and 2 were regarded as a single clinical entity because of similar clinical symptoms and blood chemical analyses. Causes of classical xanthinuria at the molecular level were unknown until recently. For classical type 1 xanthinuria, an abnormality of the xanthine dehydrogenase gene itself was hypothesized. While an abnormality in the molybdenum cofactor that is shared by both enzymes is thought to be the cause of classical type 2 xanthinuria. Recently, we reported, for the first time, a nonsense mutation and deletion of the xanthine dehydrogenase gene in four patients with classical type 1 xanthinuria, including the patients in this report (13). The
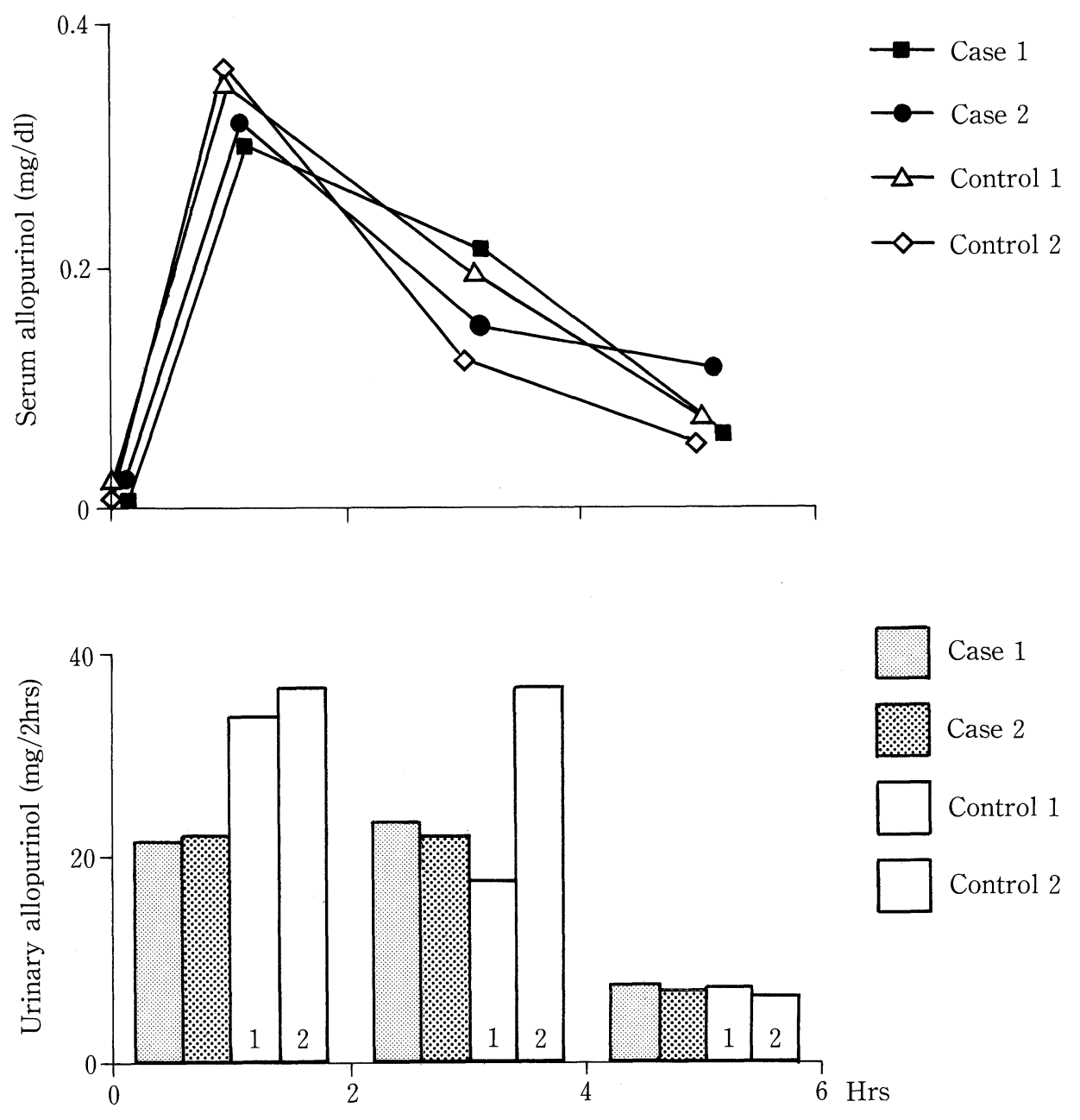

Figure 1. Allopurinol levels in serum and urine after administration of $300 \mathrm{mg}$ of allopurinol. 

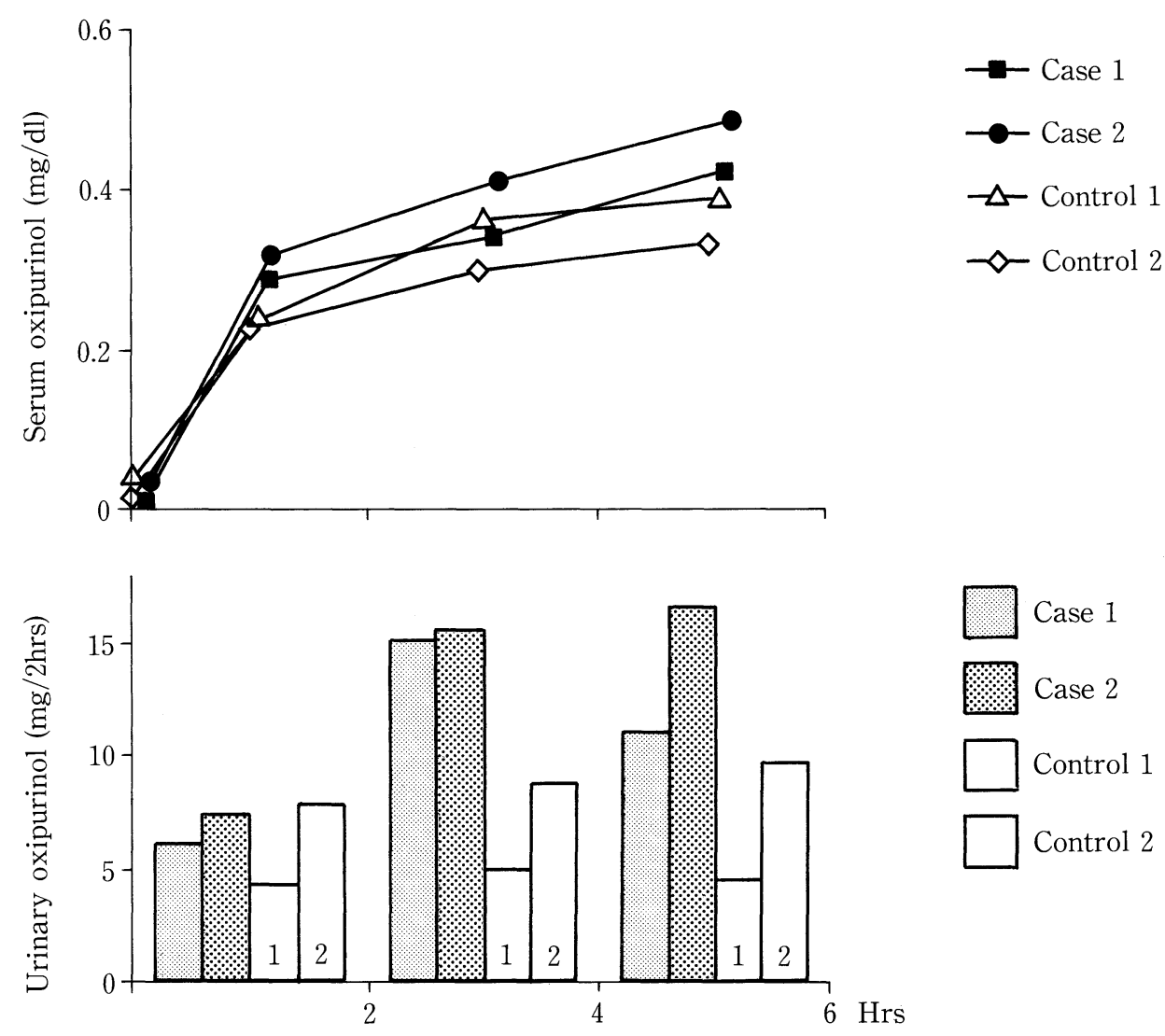

Figure 2. Oxipurinol levels in serum and urine after administration of $300 \mathrm{mg}$ of allopurinol.

present cases had a $\mathrm{C}$ to $\mathrm{T}$ base substitution at nucleotide 682 that should cause a CGA (Arg) to TGA (Ter) nonsense substitution at codon 228. As for this mutation, the patients were homozygous and their parents were heterozygous. In other words, it was confirmed that there was abnormality in xanthine dehydrogenase gene of the patients with classical type 1 xanthinuria.

Classical xanthinuria was suspected in these patients because of the typical laboratory data such as hypouricemia, hypouricosuria, and high levels of hypoxanthine and xanthine in serum and urine (14). The fact that most of the urinary total purine excretion was absolutely oxypurine meant that metabolism to uric acid was blocked. It is well known that, in addition to classical xanthinuria, no activity of xanthine dehydrogenase and aldehyde oxidase is found in molybdenum cofactor deficiency. However, molybdenum cofactor deficiency has no sulfite oxidase activity and is usually associated with severe neurological disorders such as neonatal period intractable seizures, mental retardation and coma, as well as dislocation of the lenses due to the absence of sulfite oxidase activity (15). As for these patients, the possibility of molybdenum cofactor deficiency was not considered because they had no neurological disorders. Thus, their metabolic disorder was diagnosed as classical xanthinuria type 1 due to the finding of allopurinol oxidizing activity in the allopurinol loading test and the lack of detection of xanthine dehydrogenase activity in duodenal mucosa. As for purine metabolism of the patients, the rate of serum and urinary xanthine in oxypurine were compatible with that in classical xanthinuria and the source of xanthine could have mainly been guanine as previously reported (14). The patients did not have any symptoms concerning deposition of xanthine like myositis and urolithiasis. A duodenal ulcer was found in the younger brother with classical type 1 xanthinuria, but not in the elder brother. Some patients with classical xanthinuria and duodenal ulcers have also been reported $(4,5)$. Duodenal ulcers in patients with classical xanthinuria may be related to low uric acid which is a scavenger of free radical. However, it is not certain whether the two have a cause-effect relationship or merely coexist.

There are some protocols of the allopurinol loading test for classical xanthinuria. In order to be useful in the classification of classical xanthinuria, the allopurinol loading test by this protocol must be able to separate classical xanthinuria into the two subtypes. Oxipurinol is excreted in urine, after most allopurinol is oxidized to oxipurinol within 2 to 6 hours in healthy subjects. In patients with classical xanthinuria, probably type 2 , it was reported that urinary oxipurinol was not detected even after administration of $800 \mathrm{mg}$ allopurinol, because allopurinol was not converted to oxipurinol $(16,17)$. Accordingly, obvious detection of oxipurinol indicates that a patient does not suffer 
from classical type 2 xanthinuria in the allopurinol loading test, though the result of the allopurinol loading test only was obtained for the patients with classical type 1 xanthinuria, not patients with classical type 2 xanthinuria in this report.

In most allopurinol loading tests conducted in patients with classical xanthinuria which were reported, $600-800 \mathrm{mg}$ of allopurinol was administered and the oxidation to oxipurinol was confirmed with measurement of urinary oxipurinol 4-24 hours after administration $(6,7)$. Allopurinol has various influences on metabolism such as the inhibition of orolidine-5'phosphate decarboxylase, orotatephosphoribosyltransferase, and phosphoribosyl pyrophosphate amidotransferase and rarely causes allopurinol hypersensitivity syndrome, including Stevens-Johnson syndrome and Lyell syndrome, and bone marrow suppression due to the toxicity of oxipurinol, especially in patients with renal insufficiency (18-26). Though allopurinol hypersensitivity syndrome is considered to be immunologically mediated and not dose-dependent, most other side effects of allopurinol (bone marrow suppression, exfoliative dermatitis, etc) are the result of relative overdosage of allopurinol $(22,23,25,26)$. Accordingly, less dosage of allopurinol is important for patients undergoing the allopurinol loading test, though allopurinol is not used continuously. The usual dosage of allopurinol is $100-300 \mathrm{mg} /$ day for patients with gout or hyperuricemia. The loading test was performed using $300 \mathrm{mg}$ allopurinol because Yamamoto et al reported that classical xanthinuria could be divided into two subgroups after $300 \mathrm{mg}$ of allopurinol loading and measuring allopurinol and oxipurinol in urine 4-12 hours later (5).

On the other hand, the determination of the type of classical xanthinuria from serum oxipurinol has been reported though urine collection from outpatients has been done for a long time. In this study, it was revealed that measurement of serum allopurinol and oxipurinol was useful for the classification of classical xanthinuria. It was confirmed that the measurements of allopurinol and oxipurinol in serum at 1 hour or in urine between 2 and 4 hours after administration of allopurinol are enough to determine the type of classical xanthinuria from the results of frequent measurement of allopurinol and oxipurinol in serum and urine. It is most reliable to measure allopurinol and oxipurinol in serum at 3 hours and in urine between 2 and 4 hours after administration of allopurinol because the type of classical xanthinuria for higher levels of oxipurinol in serum and urine can be easily determined.

The roles of xanthine dehydrogenase and the product, uric acid, in the body are complicated. Xanthine dehydrogenase has recently been attracting attention for its possible involvement in triggering tissue damage by producing free radicals in certain disease conditions. Many studies have been conducted on organs such as the lungs, heart, kidneys, and liver (27-30). On the other hand, uric acid that is oxidized from xanthine by xanthine dehydrogenase is a scavenger of free radicals. Classical xanthinuria is valuable because of the lack of xanthine dehydrogenase. It is considered that the incidence of complications of classical xanthinuria should be studied in the future to understand the role of xanthine dehydrogenase in diseases.

\section{References}

1) Dent CE, Philpot GR. Xanthinuria. An inborn error (or deviation) of metabolism. Lancet 266: 182, 1954.

2) Nagae A, Murakami E, Hiwada K, Sato Y, Kawachi M, Kono N. Asymptomatic hereditary xanthinuria: a case report. Jpn J Med 29: 287, 1990.

3) Kono H, Hosoya T, Kodama K, et al. Two cases of xanthinuria in brothers. Nippon Naika Gakkai Zasshi 73: 33, 1984 (in Japanese).

4) Kawachi M, Kono N, Mineo I, et al. A family of hereditary xanthinuria: Two siblings with peptic ulcer and hypouricemia due to xanthine oxidase deficiency, and a heterozygote (father) with gout. Nippon Naika Gakkai Zasshi 77: 47, 1988 (in Japanese).

5) Yamamoto T, Higashino K, Kono N, et al. Metabolism of pyrazinamide and allopurinol in hereditary xanthine oxidase deficiency. Clin Chim Acta 180: $169,1989$.

6) Simmonds HA, Levin B, and Cameron JS. Variations in allopurinol metabolism by xanthinuric subjects. Clin Sci Mol Med 47: 173, 1974.

7) Reiter S, Simmonds HA, Zollner N, Braun SL, Knedel M. Demonstration of a combined deficiency of xanthine oxidase and aldehyde oxidase in xanthinuric patients not forming oxipurinol. Clin Chim Acta 187: 221, 1990.

8) Kojima T, Nishina T, Kitamura M, Hosoya T, Nishioka K. Biochemical studies on the purine metabolism of four cases with hereditary xanthinuria. Clin Chim Acta 137: 189, 1984.

9) Hosoya T, Ichida K, Tabe A, Sakai O. A study on treatment of hyperuricemia - Effects and kinetics of allopurinol and oxipurinol. Ryumachi 31: 28, 1991 (in Japanese).

10) Lowry OH, Rosebrough NJ, Farr AL, Randall RJ. Protein measurement with the Folin phenol reagent. J Biol Chem 193: 265, 1951.

11) Ichida $K$, Amaya $Y$, Noda $K$, et al. Cloning of the cDNA encoding human xanthine dehydrogenase (oxidase): structural analysis of the protein and chromosomal location of the gene. Gene 133: 279, 1993.

12) Minoshima $S$, Wang $Y$, Ichida $K$, Nishino $T$, Shimizu N. Mapping of the gene for human xanthine dehydrogenase (oxidase) (XDH) to band $\mathrm{p} 23$ of chromosome 2. Cytogenet Cell Genet 68: 52, 1995.

13) Ichida K, Amaya Y, Kamatani N, Nishino T, Hosoya T, Sakai O. Identification of two mutations in human xanthine dehydrogenase gene responsible for classical type I xanthinuria. J Clin Invest 99: 2391, 1997.

14) Simmonds HA, Reiter S, Nishino T. Hereditary xanthinuria. in: The Metabolic and Molecular Bases of Inherited Disease, Scriver CR, Beaudet AL, Sly WS, Valle D, Eds. McGraw-Hill Inc, New York, 1995, p. 1781.

15) Johnson JL, Wadman SK. Molybdenum cofactor deficiency and isolated sulfite oxidase deficiency. in: The Metabolic and Molecular Bases of Inherited Disease, Scriver CR, Beaudet AL, Sly WS, Valle D, Eds. McGraw-Hill Inc, New York, 1995, p. 2271.

16) Engelman K, Watts RWE, Klinenberg JR, Sjoerdsma A, Seegmiller JE. Clinical, physiological and biochemical studies of a patient with xanthinuria and pheochromocytoma. Am J Med 37: 839, 1964.

17) Holmes EW Jr, Mason DH Jr, Goldstein LI, Blount RE Jr, Kelley WN. Xanthine oxidase deficiency: studies of a previously unreported case. Clin Chem 20: 1076, 1974.

18) Fox RM, Royse-Smith D, O'Sullivan WJ. Orotidinuria induced by allopurinol. Science 168: 861, 1970.

19) Kelley WN, Beardmore TD. Allopurinol: alteration in pyrimidine metabolism in man. Science 169: 388, 1970.

20) Fox IH, Wyngaarden JB, Kelley WN. Depletion of erythrocyte phosphoribosylpyrophosphate in man, a newly observed effect of allopurinol. N Engl J Med 283: 1177, 1970.

21) Kantor GL. Toxic epidermal necrolysis, azotemia, and death after allopurinol therapy. JAMA 212: 478, 1970.

22) Greenberg MS, Zambrano SS. Aplastic agranulocytosis after allopurinol therapy. Arthritis Rheum 15: 413, 1972.

23) McInnes GT, Lawson DH, Jick H. Acute adverse reactions attributed to allopurinol in hospitalized patients. Ann Rheum Dis 40: 245, 1981.

24) Hande KR, Noone RM, Stone WJ. Severe allopurinol toxicity. Descrip- 


\section{ICHIDA et al}

tion and guidelines for prevention in patients with renal insufficiency. Am J Med 76: 47, 1984.

25) Singer JZ, Wallace SL. The allopurinol hypersensitivity syndrome. Unnecessary morbidity and mortality. Arthritis Rheum 29: 82, 1986.

26) Simmonds HA, Cameron JS, Morris GS, Davies PM. Allopurinol in renal failure and the tumour lysis syndrome. Clin Chim Acta 160: 189, 1986.

27) Grum CM, Ragsdale RA, Ketai LH, Simon RH. Plasma xanthine oxidase activity in patients with ARDS. J Crit Care 2: 22, 1987.
28) McCord JM. Oxygen-derived free radicals in postischemic tissue injury. N Engl J Med 312: 159, 1985.

29) Greene EL, Paller MS. Xanthine oxidase produces $\mathrm{O}_{2}^{-} \bullet$ in posthypoxic injury of renal epithelial cells. Am J Physiol 263: F251, 1992.

30) de Groot $\mathrm{H}$, Littauer A. Reoxygenation injury in isolated hepatocytes: cell death precedes conversion of xanthine dehydrogenase to xanthine oxidase. Biochem Biophys Res Commun 155: 278, 1988. 